\title{
The role of the LDL receptor in apolipoprotein B secretion
}

\author{
Jaap Twisk, ${ }^{1,2}$ Donald L. Gillian-Daniel, ${ }^{1}$ Angie Tebon, ${ }^{1}$ Lin Wang,,${ }^{1,3}$ \\ P. Hugh R. Barrett, ${ }^{4}$ and Alan D. Attie ${ }^{1}$ \\ ${ }^{1}$ Department of Biochemistry, University of Wisconsin-Madison, Madison, Wisconsin 53706, USA \\ ${ }^{2}$ Division of Biopharmaceutics, Leiden/Amsterdam Center for Drug Research, University of Leiden, Sylvius Laboratories, 2300 \\ RA Leiden, The Netherlands \\ ${ }^{3}$ Department of Chemistry and Biochemistry, University of California-San Diego, La Jolla, California 92093, USA \\ ${ }^{4}$ Department of Medicine, University of Western Australia, Perth 6001, Australia
}

Address correspondence to: Alan Attie, Department of Biochemistry, University of Wisconsin-Madison, 433 Babcock Drive, Madison, Wisconsin 53706-1544, USA. Phone: (608) 262-1372; Fax: (608) 263-9609; E-mail: attie@biochem.wisc.edu.

Jaap Twisk and Donald L. Gillian-Daniel contributed equally to this work.

Received for publication October 6, 1999, and accepted in revised form December 28, 1999.

Familial hypercholesterolemia is caused by mutations in the LDL receptor gene $(L d l r)$. Elevated plasma LDL levels result from slower LDL catabolism and a paradoxical lipoprotein overproduction. We explored the relationship between the presence of the LDL receptor and lipoprotein secretion in hepatocytes from both wild-type and LDL receptor-deficient mice. $L d l r^{-/}$hepatocytes secreted apoB100 at a 3.5-fold higher rate than did wild-type hepatocytes. ApoB mRNA abundance, initial apoB synthetic rate, and abundance of the microsomal triglyceride transfer protein $97-\mathrm{kDa}$ subunit did not differ between wild-type and $\mathrm{Ldl}^{-/-}$cells. Pulse-chase analysis and multicompartmental modeling revealed that in wild-type hepatocytes, approximately $55 \%$ of newly synthesized apoB 100 was degraded. However, in $\mathrm{Ldll}^{-/}$cells, less than $20 \%$ of apoB was degraded. In wild-type hepatocytes, approximately equal amounts of LDL receptor-dependent apoB100 degradation occured via reuptake and presecretory mechanisms. Adenovirus-mediated overexpression of the LDL receptor in $\mathrm{Ldlr}^{-/-}$cells resulted in degradation of approximately $90 \%$ of newly synthesized apoB 100 . These studies show that the LDL receptor alters the proportion of apoB that escapes co- or post-translational presecretory degradation and mediates the reuptake of newly secreted apoB-containing lipoprotein particles.

J. Clin. Invest. 105:521-532 (2000).

\section{Introduction}

The LDL receptor plays a critical role in the regulation of plasma LDL levels by mediating approximately two thirds of LDL clearance (1-3). Loss of LDL receptor function leads to decreased LDL catabolism and elevated LDL levels (4). LDL receptor levels are affected by diet, hormones, and most dramatically, by mutations in the LDL receptor locus that lead to familial hypercholesterolemia $(\mathrm{FH})$.

Early studies of LDL metabolism in patients with FH revealed that in addition to the LDL clearance defect, they overproduce $\operatorname{LDL}(5,6)$ and relatively small VLDL particles (7). VLDL is the metabolic precursor of LDL and is converted to LDL through the action of lipoprotein lipase, a triacylglycerol lipase that acts upon VLDL while it circulates in the bloodstream (8). Increased production of VLDL can lead to increased LDL simply by providing more precursor. In addition, impaired clearance of VLDL remnants can lead to LDL overproduction (9).

A long-standing paradox in the lipoprotein field is posed by the cholesterol-lowering drugs known as statins. These drugs inhibit 3-hydroxy-3-methyl-glutaryl coenzyme A reductase, a tightly regulated step in the cholesterol biosynthetic pathway (10). Cells respond to the dearth of cholesterol by upregulating transcription of cholesterol-regulated genes, including the $\mathrm{LDL}$ receptor (11). Statins are ineffective in patients homozygous for null alleles of the LDL receptor (12). It has therefore been inferred that statins act by increasing LDL catabolism via upregulation of the LDL receptor. Paradoxically, statins do not always affect the LDL clearance rate. Rather, in many clinical studies (13-15) and animal studies $(16,17)$, statins decrease VLDL and/or LDL production (reviewed in ref. 18).

The post-translational fate of apoB, the major protein component of VLDL, can be explained by multiple mechanisms. In human and rat hepatoma cell lines, a large proportion of newly synthesized apoB is degraded within the secretory pathway (19). Thus, the rate of apoB secretion, and hence, VLDL secretion, from the liver is determined by the proportion of apoB that escapes coor post-translational degradation $(20,21)$. In addition, reuptake of newly secreted lipoproteins has also been proposed to regulate the net output of apoB (22).

How can the presence or absence of a functional LDL receptor affect the production of lipoproteins? We addressed this question by studying apoB secretion in cultured hepatocytes isolated from wild-type mice and mice lacking a functional $\mathrm{LDL}$ receptor $\left(\mathrm{Ldl}^{-/} /-\right)$. Similar to $\mathrm{FH}$, previous studies with $\mathrm{Ldlr}^{-1}$ - mice revealed a decrease in LDL clearance (23) and a marked increase in plasma apoB levels (23-26). Our results with primary hepatocytes from these animals indicate that the LDL receptor is involved 
in determining the post-translational fate of apoB by increasing presecretory apoB degradation and mediating reuptake of nascent lipoprotein particles.

\section{Methods}

Mice. Male wild-type and LDL receptor disrupted (Ldlr ${ }^{-/}$) C57BL/6J mice (23) were obtained from The Jackson Laboratory ( $L d l r^{\text {tm1Her }}$ mice; Bar Harbor, Maine, USA). The Ldlrm1Her mice were created by insertion of the neo gene into exon 4 of the LDL receptor gene in the laboratories of R. Hammer and J. Herz (University of Texas Southwestern Medical Center at Dallas, Texas, USA; ref. 23). An Sv129-derived AB1 embryonic stem cell line was used. The C57BL/6J.Ldlrtm1He strain was generated by crossing the $L d l r^{\text {tm } 1 H e r}$ mutation 5 or more times to C57BL/6J mice. For the hepatocyte experiments, mice were weaned at 3-4 weeks, given standard chow and water ad libitum, housed on a 12-hour light/dark cycle, and sacrificed at 12-14 weeks of age. Genotypes were determined using a PCR-based assay (27). Plasma cholesterol levels (Sigma Diagnostics, St. Louis, Missouri, USA) of wild-type and mutant mice were $77.6 \pm 7.4$ and $262.2 \pm 46.8 \mathrm{mg} / \mathrm{dL}$, respectively.

Preparation of primary mouse hepatocytes. Hepatocytes were isolated by liver perfusion as described elsewhere (28) and seeded at subconfluency $\left(0.8 \times 10^{6}\right.$ cells $/ 60$ $\mathrm{mm}$ dish) in DMEM (GIBCO BRL, Grand Island, New York, USA) supplemented with FBS (10\% vol/vol; HyClone Laboratories, Logan, Utah, USA), insulin (20 $\mathrm{mU} / \mathrm{mL}$; Novo Nordisk Pharmaceuticals Inc., Clayton, North Carolina, USA) and dexamethasone $(25 \mathrm{nM}$; Sigma Diagnostics). Cells were left to attach for 4 hours in an incubator at $37^{\circ} \mathrm{C}, 5 \% \mathrm{CO}_{2}$. After a wash with DMEM, cells were cultured overnight in DMEM supplemented with $10 \% \mathrm{FBS}$ and $20 \mathrm{mU} / \mathrm{mL}$ insulin. With the exception of experiments using adenovirus infection, experiments were performed within 24 hours of hepatocyte isolation.

Continuous metabolic labeling of hepatocytes. Cells were starved for 1 hour in methionine/cysteine-free DMEM (starve medium) supplemented with $0.2 \mathrm{mM}$ oleic acid (conjugated to BSA) and radiolabeled with $100 \mu \mathrm{Ci} / \mathrm{dish}$ L- $\left.{ }^{35} \mathrm{~S}\right]$ methionine/cysteine (tracer; $1,175 \mathrm{Ci} / \mathrm{mmol}$; NEN Life Science Products Inc., Boston, Massachusetts, USA) in the same medium for the indicated times.

Pulse-chase analysis. Hepatocytes were incubated for 1 hour in starve medium before pulse labeling for 7.5 minutes with tracer $(200 \mu \mathrm{Ci} / 60 \mathrm{~mm}$ dish $)$. Dishes were washed once with DMEM before addition of chase medium (chase; DMEM supplemented with 10 $\mathrm{mM}$ each of unlabeled methionine and cysteine and $0.2 \mathrm{mM}$ oleic acid). Heparin (grade 1-A; Sigma Diagnostics) was added to chase medium as indicated in the figures. All concentrations used were equally effective at rescuing apoB secretion.

Immunoprecipitation of $a p o B$, apoE, and albumin. After radiolabeling, media were collected and centrifuged (5 minutes at $100 \mathrm{~g}$ ). The resulting media were used for immunoprecipitations. Cells were rinsed 3 times with ice- cold PBS, scraped into PBS, and collected by centrifugation. The cell pellets were lysed in $200 \mu \mathrm{L}$ RIPA/1\% SDS (150 mM NaCl, $50 \mathrm{mM}$ Tris [pH 7.5], 1\% Triton X-100, $0.5 \%$ deoxycholate, $1 \%$ SDS, $1 \mathrm{mM}$ PMSF, $1 \mathrm{mM}$ orthovanadate, $10 \mu \mathrm{g} / \mathrm{mL}$ trypsin inhibitor, and $10 \mu \mathrm{g} / \mathrm{mL}$ : leupeptin) and subsequently diluted $5 \times$ to $1 \mathrm{~mL}$ final volume in $150 \mathrm{mM} \mathrm{NaCl}, 50 \mathrm{mM}$ Tris (pH 7.4), $1 \mathrm{mM}$ PMSF, $1 \mathrm{mM}$ orthovanadate, $10 \mu \mathrm{g} / \mathrm{mL}$ trypsin inhibitor, and 10 $\mu \mathrm{g} / \mathrm{mL}$ leupeptin. For immunoprecipitations, both media and cell lysates were supplemented with $1 / 5 \mathrm{vol}$ immunoprecipitation buffer (IMB; $100 \mathrm{mM}$ Tris [pH 7.4], 25 mM EDTA, 5 mg/mL BSA, 2.5\% sodium deoxycholate, $2.5 \%$ Triton $\mathrm{X}-100$, and $0.01 \%$ sodium azide), and antibodies to apoB (polyclonal, rabbit anti-pig LDL), apoE (polyclonal, rabbit anti-human apoE), or albumin (polyclonal, rabbit anti-human serum albumin; Sigma Diagnostics) were added. For immunoprecipitation of albumin, IMB did not contain BSA. After an overnight incubation at $4^{\circ} \mathrm{C}$, Protein A-agarose beads (GIBCO $\mathrm{BRL}$ ) were added and the incubation was continued at $4{ }^{\circ} \mathrm{C}$ overnight. The antibody/bead slurry was subsequently washed twice with IMB, once with PBB (10 mM phosphate buffer [pH 7.4], $1 \mathrm{mg} / \mathrm{mL}$ BSA, and 0.01\% sodium azide) and once with $\mathrm{PB}$ (PBB without $\mathrm{BSA})$. For immunoprecipitation of albumin, beads were washed 4 times with PB only. Radiolabeled protein was solubilized in SDS-sample buffer (2\% SDS, 20\% glycerol, $50 \mathrm{mM}$ Tris [pH 6.8], $6 \mathrm{M}$ urea, $1 \mathrm{mM}$ EDTA, and $20 \mathrm{mg} / \mathrm{mL}$ bromophenol blue) supplemented with $10 \mathrm{mM}$ DTT and $250 \mathrm{mM} \beta$-mercaptoethanol, and heated at $65^{\circ} \mathrm{C}$ for 30 minutes before SDS-PAGE (29). Specific proteins were viewed by autoradiography, and amounts of radiolabeled protein were determined by slicing bands from the gel, solubilizing in $\mathrm{H}_{2} \mathrm{O}_{2}: \mathrm{HClO}_{4}(2: 1)$ at $65^{\circ} \mathrm{C}$ overnight, and quantitating radioactivity in a liquid scintillation counter (LSC; Packard Instrument Co., Meriden, Connecticut, USA). Alternatively, amounts of radiolabeled protein were determined by Phosphorimager quantitation (Image Quant version 3.3; Molecular Dynamics, Sunnyvale, California, USA). All data were normalized to cellular protein (30) and total TCA-precipitable radioactivity.

Multicompartmental modeling of apoB production. Estimates of apoB secretion and degradation were determined by multicompartmental modeling of pulsechase data using the SAAM II program (SAAM Institute, Seattle, Washington, USA), similar to Wilcox et al. (31). The model was developed using apoB radioactivity data from both wild-type and $\mathrm{Ldlr}^{-1-}$ hepatocytes simultaneously; the best fit to the data was one in which the fewest parameters (i.e., those for "loss" of apoB, as detailed later) were changed between wild-type and $L d l r^{-/}$data sets. A simplified description of the model follows. In Figure 1, compartments 1-8, 10, and 12 are intracellular, whereas compartment 9 represents apoB secreted into the media. Compartment 1 represents the amino acid tracer pool (i.e., $\left.{ }^{[35} \mathrm{S}\right]$ methionine). Uptake of tracer by cells and its incorporation into apoB peptide is assumed to occur instantaneously. Compartments 2-7 represent incorporation of tracer 
amino acid into progressively longer nascent apoB polypeptide chains during translation. Compartment 7 represents the first appearance of a pool of full-length protein (either apoB100 or apoB48). The data sets for modeling are based on experimental measurements of either full-length apoB100 or apoB48.

To optimize the fit of the data, a delay compartment was introduced into the model; compartment 8 represents a delay in the time required to observe full-length apoB in the media. Because apoB100 radioactivity appeared more slowly in the media than did apoB48, an extended delay, compartment 12 , was required in the model. To enable a best fit to the experimental data, apoB radioactivity was allowed to distribute between intracellular compartments $7,8,10$, and 12. Intracellular compartments 7, 8, and 10 were determined experimentally and thus were sampled in the model (hatched symbols in Figure 1). To fit the degradation rate observed in the experimental data, apoB loss occurs as rapid, presecretory degradation from compartment $7(\mathrm{k}(0,7))$, as slow, presecretory degradation from compartment $10(\mathrm{k}(0,10))$, and as heparininhibitable degradation from compartment $8(\mathrm{k}(0,8))$. ApoB loss from compartment 8 represents apoB that leaves the secretory pathway, but through an interaction with the LDL receptor is subsequently internalized and degraded. The extracellular compartment 9 represents apoB radioactivity in the media; experimental data from secreted apoB were assigned to this compartment, and apoB secretion is defined in terms of the rate constant, $\mathrm{k}(9,12)$. Compartment 9 was determined experimentally and thus was sampled in the model (hatched circle in Figure 1). Additional pathways (i.e., apoB secretion directly from compartment 10) were not required to fit the model to the experimental data. Importantly, the wild-type and Ldlr/- experimental data sets could not be described by simply switching on or off the loss of apoB attributed to the kinetic parameter, $\mathrm{k}(0,8)$; both data sets required a model that included presecretory apoB degradation. Finally, the kinetics of albumin production were determined using the same model as was used for apoB. The parameters for the degradation pathways described by the rate constants $\mathrm{k}(0,7), \mathrm{k}(0,8)$, and $\mathrm{k}(0,9)$, reached a lower limit of zero for albumin when this model was used, suggesting no loss of albumin via these pathways.

Analysis of total intracellular lipid. Cells were radiolabeled for 18 hours with $5 \mu \mathrm{Ci} /$ dish $\left[{ }^{14} \mathrm{C}\right]$ acetate in DMEM/10\% lipoprotein-deficient serum (LPDS) (32). Media were discarded and cells lysed in PBS by 10 passages through a $25 \mathrm{G}$ needle, followed by 5 minutes of sonication. Lipid was extracted from cell lysates (33), dried under $\mathrm{N}_{2}$, solubilized in chloroform, and separated on thin-layer chromatography (TLC) plates using 2 solvent systems: (a) diethylether:benzene:ethanol:actetic acid (40:50:2:0.2) and (b) diethylether:hexane (6:94). Specific bands were identified by comigration with standards; bands were scraped, solubilized in hexane, and quantitated by LSC.

Isolation of total RNA and determination of steady-state levels of apoB $m R N A$. Total RNA was isolated from cultured hepatocytes (34) and analyzed by Northern blotting.

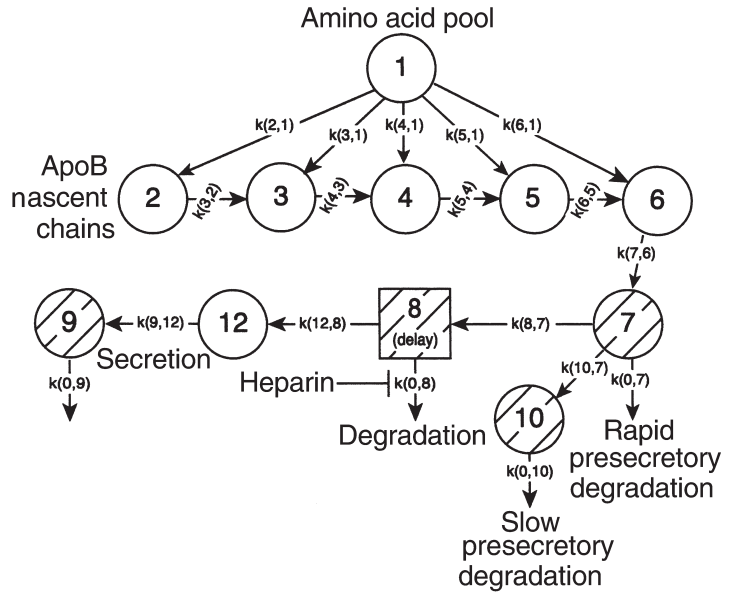

\section{Figure 1}

Multicompartmental model describing secretion and intracellular degradation of apoB. Compartments 1-8, 10, and 12 represent intracellular apoB, whereas compartment 9 represents apoB secreted into the media. Compartment 1 represents the radioactive amino acid tracer pool. Compartments 2-7 represent incorporation of tracer into progressively longer fractional lengths of nascent apoB during translation; compartment 7 represents the first appearance of a pool of full-length protein. ApoB can be lost from compartment 7 via a rapid presecretory degradation pathway or can pass on to compartment 8 or 10 . Loss of apoB from compartment 10 occurs through a slow presecretory degradation pathway. Compartment 8 represents the delay in apoB appearance in the media; compartment 12 represents the experimentally observed extended delay in apoB100 appearance in the media relative to apoB48. Loss of apoB from compartment 8 occurs via a degradation pathway that is inhibited by heparin addition. Compartment 9 represents apoB in the media. Experimentally determined apoB radioactivity is indicated by the hatched compartments 7-10.

The 14-kb apoB mRNA was identified using a radiolabeled 1,100 bp Sac1/Hpa1 fragment of apoB cDNA isolated from pB48LII (MegaPrime labeling kit; Amersham Pharmacia Biotech Inc., Piscataway, New Jersey, USA; ref. 35). GAPDH mRNA was used as an internal standard and identified using a 1,200-bp Pst 1 fragment isolated from rat GAPDH cDNA (36). ApoB mRNA abundance was determined by dot blotting using probes described elsewhere (37). Radioactivity was quantitated by Phosphorimager and expressed as a ratio of apoB mRNA/GAPDH mRNA.

Western analysis of microsomal triglyceride transfer protein $97-k D a$ subunit. Cells were lysed and protein solubilized in SDS-sample buffer. Total protein concentration in each sample was determined (30). Samples containing equivalent amounts of total protein were loaded in each lane, and proteins were separated by SDS-PAGE. Proteins were transferred to nitrocellulose membrane following manufacturer's recommendations (Bio-Rad Laboratories Inc., Hercules, California, USA), and membranes blotted using a 97-kDa subunit antibody (a kind gift of H. Jamil, Bristol-Myers Squibb Co., Seattle, Washington, USA). Blots were reprobed using antibodies to albumin (polyclonal, rabbit anti-human serum albumin; Sigma Diagnostics). 
Treatment of hepatocytes with recombinant adenovirus. Adenovirus-mediated overexpression of the LDL receptor was performed essentially as described previously (38). Briefly, after the first overnight incubation in DMEM supplemented with $10 \%$ FBS and $20 \mathrm{mU} / \mathrm{mL}$ insulin, cells were washed with serum-free DMEM. Hepatocytes were treated with pAdCMV-LDLR (an adenovirus with the human LDL receptor CDNA; a generous gift from J. Wilson, University of Pennsylvania, Philadelphia, Pennsylvania, USA) at an moi of 40-50 for 2 hours at $37^{\circ} \mathrm{C}$ with gentle, intermittent rocking. The medium was then replaced with DMEM containing $2 \mathrm{mM}$ L-glutamine, $1 \mathrm{mM}$ sodium pyruvate, 100 $\mathrm{U} / \mathrm{mL}$ penicillin, $100 \mu \mathrm{g} / \mathrm{mL}$ streptomycin, $10 \mathrm{nM}$ dexamethasone, $10 \mathrm{mU} / \mathrm{mL}$ insulin, and $0.2 \%$ FBS. To enable full expression of the adenovirus-transferred LDL receptor gene, cells were incubated an additional 36-48 hours in the same medium (changed after 24 hours) at $37^{\circ} \mathrm{C}, 5 \% \mathrm{CO}_{2}$. Experimental manipulations
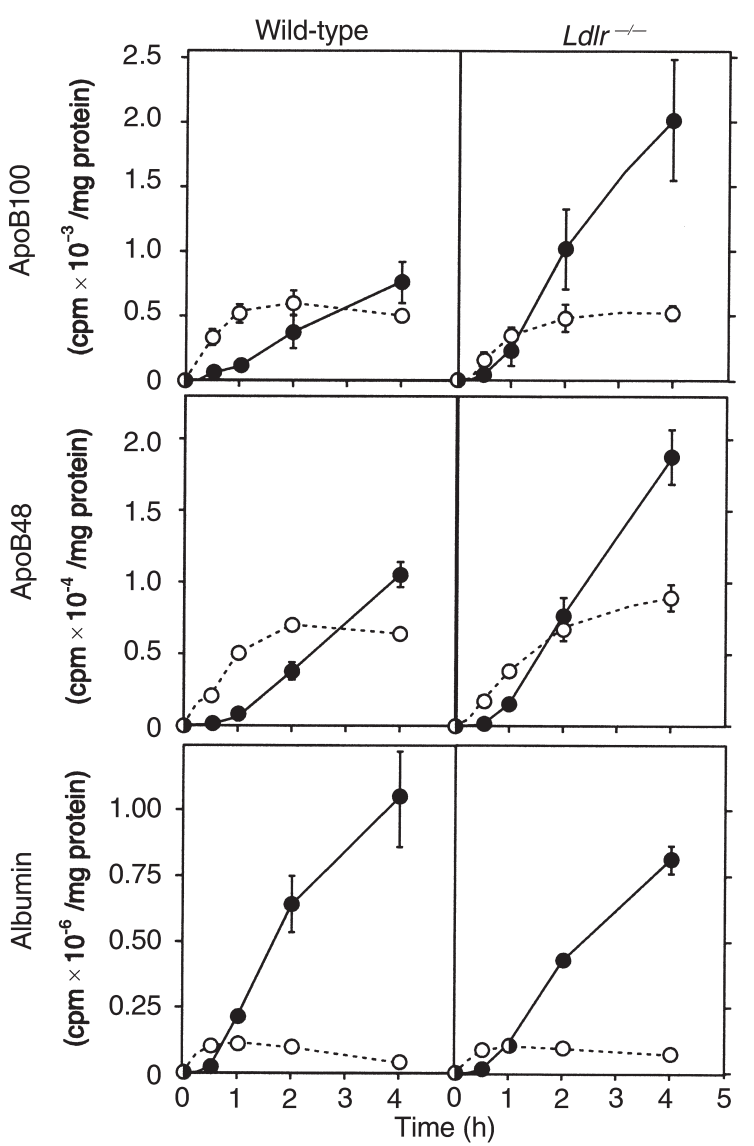

Figure 2

Determination of apoB secretion rate in the presence and absence of a functional LDL receptor. Hepatocytes from wild-type and $L d l r^{-1}$ mice were radiolabeled continuously with $\left[{ }^{35} \mathrm{~S}\right]$ methionine/cysteine, and samples were collected at the times indicated. Cells were lysed, and both media and cell lysates immunoprecipitated with antiserum raised against either apoB or albumin. Samples were separated on $5 \%$ or $8 \%$ SDS-polyacrylamide gels, respectively, and apoB and albumin radioactivity quantitated. Results are mean \pm SEM of duplicate dishes from 5 independent isolations for apoB and 3 independent isolations for albumin. Open circle, intracellular protein; filled circle, secreted protein. were performed as detailed in the text. Finally, a $\beta$ galactosidase-expressing adenovirus (pAdCMV- $\beta$-gal; Quantum Biotechnologies Inc., Laval, Quebec, Canada) was used as a control for nonspecific effects due either to adenovirus infection of hepatocytes or to exogenous protein overexpression.

\section{Results}

The rate of $a p o B$ secretion increases in the absence of a functional $L D L$ receptor. The rate of $\mathrm{apoB} 100$ and apoB 48 secretion was 3- to 4-fold and 1.5- to 2.0-fold higher, respectively, in $\mathrm{Ldlr}^{\prime-}$ cells than in wild-type hepatocytes (Figure 2). The apoB secretion rate was determined by radiolabeling cells continuously for up to 4 hours with ${ }^{[35}$ S] methionine/cysteine. Both full-length apoB (apoB100) and apoB48, a truncated form of apoB, produced as a consequence of mRNA editing (39), are produced in mouse hepatocytes (40). Hepatocytes were cultured for up to 24 hours before the start of the experiments. Both wild-type and $\mathrm{Ldlr}^{-/}$ hepatocytes synthesized and secreted approximately 5-10 times more apoB48 than apoB100, consistent with prior observations (Figure 2; ref. 41). In parallel with apoB, total apoE secretion was approximately 1.5 -fold higher from $\mathrm{Ldlr}^{/-}$hepatocytes than from wild-type cells (data not shown). This result is similar to observations of lipoproteins from LDL receptor-deficient patients $(7,42)$.

In contrast to apoB, secretion of albumin was not significantly different between wild-type and mutant hepatocytes (Figure 2). The amount of total TCA-precipitable $\left[{ }^{35} \mathrm{~S}\right]$-labeled protein was similar in wild-type and $\mathrm{Ldl} \mathrm{r}^{-/}$ hepatocytes (data not shown). Both results indicate that the absence of the LDL receptor does not cause marked changes in overall protein synthesis or secretion.

Steady-state levels of $a p o B m R N A$ and initial $a p o B$ synthesis rates are similar in wild-type and $L_{d l r^{-1}}$ hepatocytes. To determine whether the difference in apoB secretion between cell types could be accounted for by a difference in apoB synthetic capacity, both the apoB mRNA abundance and the apoB protein synthetic rate were measured. Our probe hybridized to the expected $14-\mathrm{kb}$ apoB mRNA transcript by Northern blot (data not shown). By slot blot, the abundance of apoB mRNA (relative to that of GAPDH) was the same in wild-type and $L d l r^{-1}$ hepatocytes (Figure 3a).

To determine the initial apoB synthesis rate, both wildtype and $\mathrm{Ldl}^{/-}$hepatocytes were radiolabeled for 5,15 , or 30 minutes with $\left[{ }^{35} \mathrm{~S}\right]$ methionine/cysteine. As there is no appreciable apoB secretion during this time interval, only intracellular apoB levels were measured. The apoB100 and apoB48 synthetic rates were similar in wild-type and $\mathrm{Ldl} / \mathrm{r}^{-}$ hepatocytes (Figure 3b). Similarly, no difference in the albumin synthesis rate was observed (Figure $3 \mathrm{~b}$ ).

ApoB secretion is not affected by intracellular neutral lipid levels in wild-type and Ldlr/- hepatocytes. Both intracellular triglyceride and cholesterol ester levels have been invoked as regulators of post-translational apoB degradation $(20,43)$. ApoB secretion also depends on microsomal triglyceride transfer protein (MTP)-catalyzed lipid transfer (reviewed in ref. 44). We therefore charac- 


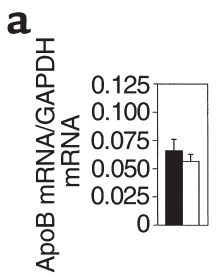

b

Figure 3

Determination of steady-state levels of apoB mRNA and apoB initial synthesis rates in wild-type and $L d l r^{-1-}$ hepatocytes. (a) Steady-state levels of apoB mRNA. ApoB mRNA abundance was measured by slot blot. The results are expressed as a ratio of apoB/GAPDH (mean \pm SEM; 2 independent isolations, up to 8 samples per isolation). (b) Initial synthesis rates for apoB100, apoB48, and albumin. Samples were treated as described in Figure 2, except that cells were labeled with $\left[{ }^{35} \mathrm{~S}\right]$ methionine/cysteine for 5, 15, and 30 minutes. Results shown are a mean \pm SEM of duplicate dishes from 4 independent hepatocyte isolations for apoB, and 3 independent isolations for albumin. Filled bars, wild-type; open bars, $L d l r^{-1}$.

terized both intracellular lipid levels and MTP 97-kDa subunit levels in both cell types. Neutral lipids were labeled to steady-state by incubation of hepatocytes for 18 hours with $\left[{ }^{14} \mathrm{C}\right]$ acetate. Intracellular triglyceride levels were 2 -fold higher in $\mathrm{Ldl}^{-/}$- cells relative to wild-type hepatocytes (Table 1). Triglyceride mass measurements (data not shown) correlated well with steady-state $\left[{ }^{14} \mathrm{C}\right]$ triglyceride levels. Free and esterified cholesterol levels did not differ significantly in the 2 cell types.

When hepatocytes were incubated in $0.8 \mathrm{mM}$ oleic acid, instead of the standard $0.2 \mathrm{mM}$, the intracellular triglyceride mass was elevated to similar levels in both cell types ( 253 and $287 \mu \mathrm{g} / \mathrm{mg}$ cellular protein for wildtype and $L d l r^{-1}$ hepatocytes, respectively). Nevertheless, apoB secretion rates were still increased in $\mathrm{Ldlr}^{-/}$cells to the same extent as they were in the presence of 0.2 $\mathrm{mM}$ of oleic acid; approximately 3 -fold and 1.8-fold more apoB100 and apoB48, respectively, were secreted from $L d l r^{-1}$ cells, relative to wild-type hepatocytes.

The level of MTP has been shown to be rate limiting for apoB secretion $(45,46)$. Therefore, we measured relative MTP 97-kDa subunit mass by Western blot analysis of hepatocyte lysate from four animals of each LDL receptor genotype. Expression levels of the $97 \mathrm{kDa}$ subunit were corrected for the level of albumin in each sample and found to be essentially the same in both cell types (results are expressed as a ratio of MTP-97 kDa subunit/albumin; mean values with SEM of $0.304 \pm 0.04$ and $0.330 \pm 0.04$ for wild-type and $\mathrm{Ldlr}^{-/}$samples, respectively; $P=\mathrm{NS}$ ).

These results demonstrate that the presence or absence of the LDL receptor, and not triglyceride mass, cholesterol ester levels, or MTP 97-kDa subunit levels, determines the difference in apoB secretion between wild-type and $L d l r^{-/}$cells.

The $L D L$ receptor promotes both presecretory degradation and reuptake of $a p o B$. Given that the absence of the LDL receptor affects neither the rate of apoB synthesis nor the hepatocyte's capacity to transfer lipid, we carried out pulsechase experiments to determine a possible link between the LDL receptor and post-translational apoB degradation. Hepatocytes were radiolabeled with $\left[{ }^{35} \mathrm{~S}\right]$ methionine/cysteine using a 7.5-minute pulse. Cells were then chased in the presence of excess unlabeled methionine and cysteine for up to 4 hours. In addition, cells were incubated during the chase in the absence or presence of heparin $(10 \mathrm{mg} / \mathrm{mL})$ to prevent binding of newly secreted lipoproteins to both the LDL receptor and cell-surface proteoglycans (47). Multicompartmental modeling was used to estimate the extent of apoB secretion and degradation under the various experimental conditions.

The kinetic parameters generated by the multicompartmental model are depicted in Figure 1 and are summarized in Table 2. (See Tables 3-5, http://www.jci.org/, for supplementary data for specific multicompartmental model rates). The rate constant $\mathrm{k}(0,7)$ represents the fraction of apoB synthesized that is subject to a rapid process of presecretory degradation, whereas $\mathrm{k}(10,7)$ represents the fraction of apoB that is subject to a slow process of presecretory degradation. The rate constant $\mathrm{k}(8,7)$ represents the fraction of synthesized apoB destined for secretion. Finally, the fraction of apoB subject to degradation by a process that is inhibited upon heparin addition is represented by the rate constant $k(0,8)$. The percent of apoB that was either degraded or secreted was calculated from these rate constants (Table 2).

In the absence of the LDL receptor, post-translational degradation of apoB100 and apoB48 was markedly reduced (Figure 4a). Approximately $80 \%$ of apoB100 and $82 \%$ of apoB 48 were secreted from the $\mathrm{Ldlr} /$ cells, as estimated by modeling (Table 2). In striking contrast, in wildtype cells, only $46 \%$ of newly synthesized apoB100 was secreted. A similar proportion (42\%) of newly synthesized apoB48 was secreted. In contrast, $92 \%$ of albumin was secreted from both wild-type and $\mathrm{Ldll}^{-/}$hepatocytes (Figure 4b; see Table 5, http://www.jci.org/, for supplementary data). Similar to the continuous incubation experiment in Figure 2, total TCA-precipitable counts were similar between wild-type and $L d l r^{-1-}$ hepatocytes.

Based on multicompartmental modeling of the total amounts of apoB synthesized, approximately $34 \%$ of apoB100 and $40 \%$ of apoB 48 were degraded via LDL receptor-dependent processes (apoB secretion in wildtype cells subtracted from secretion in $\mathrm{Ldlr}^{-/}$hepatocytes; Table 2). To determine to what extent this degradation was due to LDL receptor-mediated reuptake

\section{Table 1}

Analysis of intracellular neutral lipid levels

\begin{tabular}{|c|c|c|c|c|}
\hline & $n$ & Wild-type & Ldl/ ${ }^{-/}$ & $t$ test \\
\hline & \multicolumn{4}{|c|}{$\mathrm{cpm} / \mathrm{mg}$ cellular protein } \\
\hline Triglyceride ${ }^{A}$ & 3 & $340,401 \pm 42,454$ & $671,616 \pm 38,398$ & $P<0.001$ \\
\hline Free cholesterol & 3 & $46,110 \pm 3,357$ & $41,710 \pm 3684$ & NS \\
\hline Cholesterol ester & 3 & $10,563 \pm 1,379$ & $6,978 \pm 1,292$ & NS \\
\hline
\end{tabular}

A Hepatocytes were radiolabeled for 18 hours with $\left[{ }^{14} \mathrm{C}\right]$ acetate in DMEM $/ 10 \%$ LPDS/0.2 mM oleic acid. Radiolabeled neutral lipids were extracted, analyzed by TLC, and quantitated by LSC. Results represent mean \pm SEM from 3 independent hepatocyte isolations, each with duplicate samples. 


\section{Figure 4}

(a) Pulse-chase analysis of apoB. Cells were metabolically labeled for 7.5 minutes with $\left[{ }^{35}\right.$ S]methionine/cysteine. After a wash, cells were incubated in chase medium supplemented with unlabeled methionine and cysteine for the indicated times, in the presence or absence of heparin $(10 \mathrm{mg} / \mathrm{mL})$. Samples were treated as described in Figure 2. The results presented represent the multicompartmental modeling fit to the data (mean data \pm SEM) from pulse-chase experiments. Data points represent the observed mean data, and the lines are the best fit to the data generated by the kinetic model. $n=6$ independent hepatocyte isolations, duplicate samples, for wildtype; 5 isolations for wild-type with heparin; 3 isolations for $\mathrm{Ldll}^{-1-}$; and a single isolation for $L d l r^{-1}$ with heparin (repeated twice). Open circle, intracellular protein; filled circle, secreted protein. (b) Pulse-chase analysis of albumin. Samples in Figure 4a were split at time of collection, and albumin was immunoprecipitated as described in Figure 2. The results presented are from 6 independent hepatocyte isolations, duplicate samples, for wild-type; 5 isolations for wild-type with heparin; 4 isolations for $L d / r^{-1}$; and 2 isolations for $L d l r^{-1-}$ with heparin. Open circle, intracellular protein; filled circle, secreted protein. a
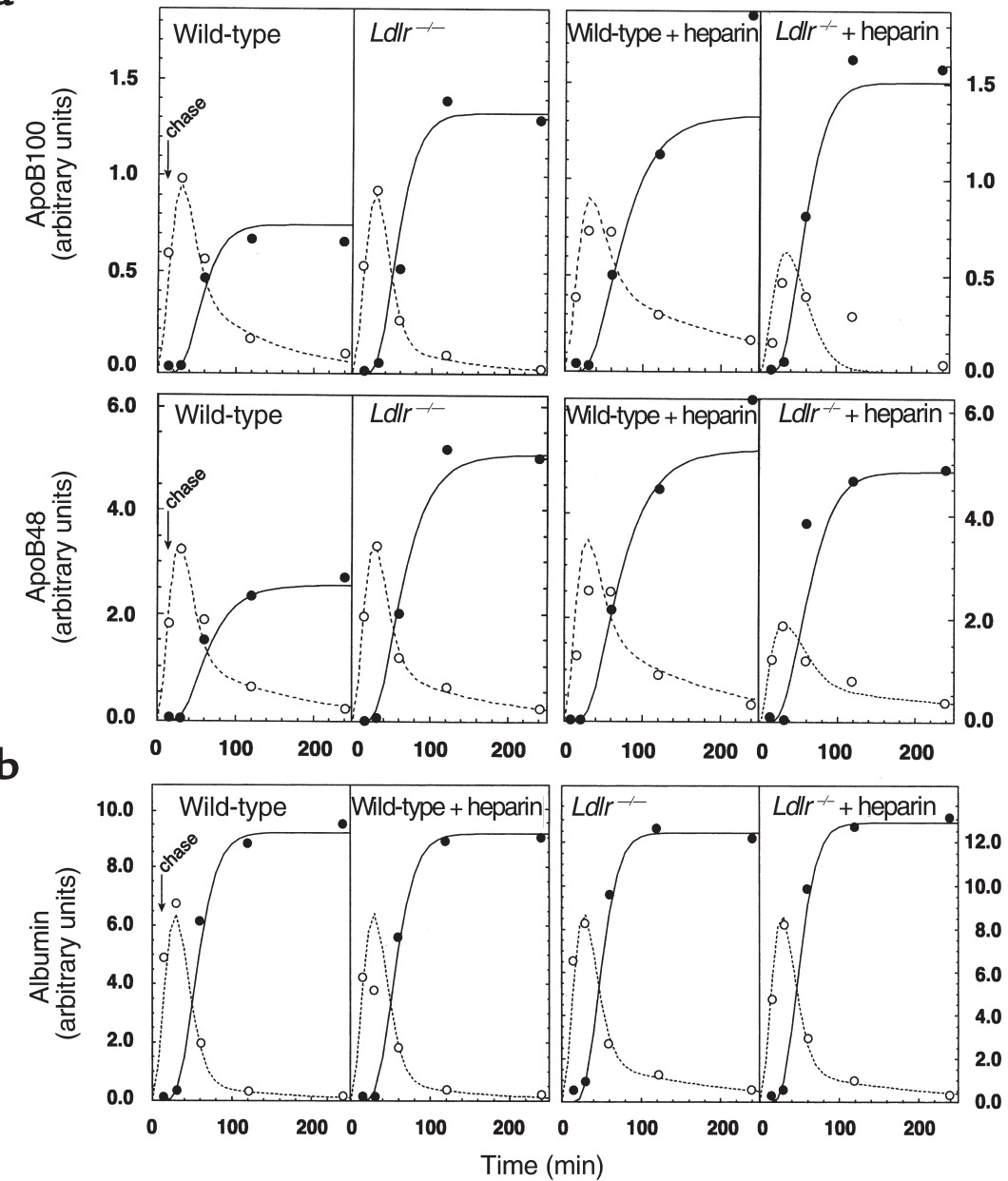

and subsequent turnover of apoB, heparin was added to the chase medium. Heparin addition partially rescued both apoB100 and apoB48 from degradation in wild-type cells (Figure 4a) but had no effect on albumin degradation in either cell type (Figure 4b). Even given the best fit to the data, the kinetic model was unable to fit the 4-hour time point for secretion of either apoB100 or apoB48 in the presence of heparin from wild-type hepatocytes (Figure 4a). In addition, some of the effects of heparin on apoB secretion were also evident in $\mathrm{Ldll}^{-/}$- hepatocytes (Figure 4a; Table 2). Thus, not all of heparin's actions occur through inhibition of an interaction with the LDL receptor.

Inclusion of postsecretion, heparin-sensitive loss of apoB in the multicompartmental model (expressed as $\mathrm{k}(0,8))$ enabled us to estimate that of the total pool of apoB synthesized, approximately $18 \%$ of apoB 100 and $38 \%$ of apoB 48 were degraded by this process. The remainder of apoB degradation occurred via intracellular presecretory mechanisms that were both dependent on, as well as independent of, the presence of a functional LDL receptor. Based on levels of apoB secreted from hepatocytes treated with heparin (secretion from wild-type cells with heparin subtracted from secretion from $L d l r^{-/}$hepatocytes with heparin; Table 2 ), approximately $23 \%$ of total synthesized apoB100 and $12 \%$ of apoB48 were degraded via an LDL receptor-dependent mechanism unrelated to reuptake.

When the results are considered as a percentage of apoB degradation occurring via LDL receptor-dependent mechanisms, approximately equal amounts of apoB100 were degraded via reuptake and presecretory mechanisms. In contrast, a majority of apoB 48 was degraded by the heparin-sensitive (i.e., reuptake) pathway.

Adenovirus-mediated overexpression of the $L D L$ receptor restores degradation of apoB in $\mathrm{Ldl}^{-1}$ - hepatocytes. Because the presence of the LDL receptor affected both pre- and postsecretory mechanisms of apoB degradation, we predicted that overexpression of the LDL receptor in the mutant cells would result in enhanced degradation of apoB. We introduced the human $\mathrm{LDL}$ receptor in $\mathrm{Ldlr}^{-/}$ cells by infection with an adenovirus containing the LDL receptor gene under control of the cytomegalovirus (CMV) promoter. An adenovirus containing the $\beta$-galactosidase gene was used as a control for nonspecific effects due to adenoviral infection and exogenous protein overexpression. Cells were subsequently pulsed with $\left[{ }^{35} \mathrm{~S}\right]$ methionine/cysteine for 7.5 minutes and chased for either 30 minutes or 2 hours.

Overexpression of the LDL receptor in $\mathrm{Ldlr}^{/-}$hepatocytes resulted in a striking decrease in both apoB100 and apoB48 secretion (Figure 5, lane 8 versus lane 13, 
marked with an asterisk). ApoB100 secretion was reduced by more than $90 \%$, and apoB 48 secretion, by approximately $50 \%$. This reduction in secreted apoB when the LDL receptor was overexpressed is greater than that observed in wild-type hepatocytes containing endogenous LDL receptor levels (Figure 5, lane 4 versus lane 13). ApoB secretion was not affected by infection with an adenovirus containing the $\beta$-galactosidase gene (Figure 5, lane 8 versus lane 14).

Albumin secretion was unaffected by overexpression of exogenous LDL receptor, demonstrating that the effect is specific for apoB (Figure 5, lanes 8, 13, and 14). LDL receptor expression also did not alter total TCAprecipitable protein levels (data not shown). In hepatocytes cultured for 3 days after isolation, up to 3 -fold more apoB100 was produced relative to apoB48. This is in contrast to the 5- to 10-fold higher levels of apoB48 observed 24 hours after isolation (Figure 2).

Overexpression of the $L D L$ receptor enhances presecretory degradation of apoB in Ldlr/- hepatocytes. Elevated levels of LDL receptor expression might account for the enhanced degradation of apoB observed in Figure 5 by increasing LDL receptor-mediated reuptake of nascent lipoprotein particles at the cell surface. This would be consistent with heparin-mediated rescue of apoB secretion (Figure 4a; Table 2). However, overexpression of the LDL receptor resulted in approximately a 30\% decrease in intracellular apoB100 at a time that precedes apoB100 secretion (Figure 5, lane 5 versus lane 9), suggesting an increase in presecretory apoB degradation.

To investigate directly whether LDL receptor overexpression affected the presecretory fate of apoB, we pulse labeled hepatocytes and measured intracellular apoB levels during a chase period preceding apoB secretion. $L d l r^{-1}$ hepatocytes were infected with LDL receptor adenovirus and 48 hours after infection, were pulse labeled with $\left[{ }^{35} \mathrm{~S}\right]$ methionine/cysteine for 7.5 minutes, and chased in the presence of heparin $(6 \mathrm{mg} / \mathrm{mL})$ for the indicated times (Figure 6). LDL receptor overexpression markedly reduced the intracellular accumulation of both apoB100 and apoB48, as assessed after 15 minutes of chase (Figure 6). In striking contrast, the rate of albumin accumulation was unaffected (Figure 6). Also, apoB accumulation in cells infected with adenovirus containing the $\beta$-galactosidase gene was not reduced relative to that observed in control cells (data not shown). These results indicate a direct effect of LDL receptor overexpression on the presecretory fate of apoB.

\section{Discussion}

Our study demonstrates for the first time a direct link between LDL receptor function and apoB secretion. Hepatocytes lacking a functional LDL receptor secrete apoB at a higher rate than wild-type hepatocytes. The higher secretion rate for apoB in $L d l r /-$ hepatocytes is not a consequence of a larger capacity to synthesize apoB: steady-state apoB mRNA levels and initial synthesis were unchanged. Nor is it due to a difference in lipid transfer capacity or intracellular triglyceride pool size.
Instead, increased secretion resulted from a greater proportion of newly synthesized apoB escaping degradation. Our findings show that the LDL receptor mediates degradation of apoB before secretion and also mediates reuptake and degradation of newly secreted apoB.

A higher secretion rate for apoB100 and apoB48 in $L d l r^{-1}$ hepatocytes is consistent with previous studies with both $\mathrm{Ldlr}^{-/}$and $\mathrm{Ldlr}^{-/}$Apobec1 $1^{-/-}$mice. A marked increase in plasma levels of both apoB100 and apoB48 were observed in $\mathrm{Ldll}^{-/}$mice (23-26), whereas plasma apoB100 levels in $\mathrm{Ldlr}^{-/}$Apobec1-/- mice were significantly higher than those observed in mice deficient for the apoB mRNA editing enzyme alone (Apobec1-/; ref. 48). Recently, Veniant et al. (49) demonstrated a large increase in plasma apoB48 levels in Apob ${ }^{48 / 48}$ mice upon loss of the LDL receptor ( $\mathrm{Ldlr}^{--} \mathrm{Apob} \mathrm{b}^{48 / 48}$ ). They suggest that the LDL receptor plays a significant role in clearing apoB48containing lipoprotein particles, via particle-associated apoE (50), an interpretation consistent with our findings.

In hepatoma cell lines, the concentration of exogenously supplied FFA influences the proportion of newly synthesized apoB that escapes post-translational degradation (reviewed in refs. 20, 21). However, this appears to be a characteristic of cell lines with a lower lipogenesis rate than hepatocytes: in primary hepatocytes, oleate does not affect the level of apoB secretion (or post-translational apoB degradation; refs. 19, 51). Consistent with these results, addition of a high concentration of exogenous oleate also did not affect the level of apoB secretion from wild-type hepatocytes relative to $L d l r^{-1}$ hepatocytes.

\section{Table 2}

Apolipoprotein secretion and degradation

\begin{tabular}{|c|c|c|c|c|}
\hline & \multicolumn{2}{|c|}{ ApoB100 } & \multicolumn{2}{|c|}{ ApoB48 } \\
\hline & Wild-type & $L_{d l r^{\prime-}}$ & Wild-type & Ldlr' \\
\hline & \multicolumn{2}{|c|}{$\%$ of total } & \multicolumn{2}{|c|}{$\%$ of total } \\
\hline Presecretory degradation & & & & \\
\hline Fast degradation ${ }^{\mathrm{A}}$ & 7.7 & 9.7 & 0.0 & 0.0 \\
\hline Slow degradation ${ }^{B}$ & 29.3 & 10.7 & 20.5 & 18.0 \\
\hline Destined for secretion ${ }^{C}$ & 63.1 & 79.7 & 79.5 & 82.0 \\
\hline Postsecretory degradation & 176 & 00 & 378 & 00 \\
\hline Secretion ${ }^{\mathrm{E}}$ & 45.5 & 79.7 & 41.6 & 82.0 \\
\hline plus heparin & 72.8 & 95.5 & 73.7 & 85.4 \\
\hline
\end{tabular}

Pulse-chase data for apoB100 and apoB48 from wild-type and $L d / r^{-1-}$ hepatocytes were analyzed by multicompartmental modeling. The percent of the total amount of apoB synthesized that is secreted as well as degraded by various pathways was determined from the kinetic modeling. Parameters used in the calculations are given in Tables 3 and 4 (see http://www.jci.org/ for supplementary data). (Fast degradation) + (slow degradation $)+($ protein destined for secretion $)=100 \% ;($ fast degradation $)$ + (slow degradation) + (postsecretory degradation inhibited by heparin) $+($ secretion $)=100 \%$. ${ }^{A}$ Direct degradation from compartment $7, k(0,7)$, calculated using the formula: $[\mathrm{k}(0,7) /(\mathrm{k}(0,7)+\mathrm{k}(8,7)+\mathrm{k}(10,7))] \times 100$. ${ }^{B}$ Degradation from compartment 7 via compartment $10, k(10,7)$, calculated using the formula: $[k(10,7) /(k(0,7)+k(8,7)+k(10,7))] \times 100$. CProtein destined for secretion, $k(8,7)$, calculated using the formula: $[k(8,7) /(k(0,7)+k(8,7)+k(10,7))] \times 100$. DDegradation from compartment $8, k(0,8)$, calculated using the formula: $[\mathrm{k}(8,7) /(\mathrm{k}(0,7)+\mathrm{k}(8,7)+$ $k(10,7))] \times[k(0,8) /(k(0,8)+k(12,8))] \times 100$. EProtein secreted from the cell, $\mathrm{k}(9,12)$, calculated using the formula: $[\mathrm{k}(12,8) /(\mathrm{k}(0,8)+\mathrm{k}(12,8))] \times$ $[k(8,7) /(k(0,7)+k(8,7)+k(10,7))] \times 100$. 


\section{Figure 5}

Determination of apoB and albumin secretion after adenovirusmediated overexpression of the human LDL receptor. Wild-type and $L d / r^{-1-}$ hepatocytes were infected with adenovirus containing either the LDL receptor gene, or the gene encoding $\beta$-galactosidase (Ad $\beta$-gal), both under control of the CMV promoter. After infection, cells were incubated a further $36-48$ hours. Cells were radiolabeled for 7.5 minutes with $\left[{ }^{35} \mathrm{~S}\right]$ methionine/cysteine, washed once, and chased for the indicated times. The data shown at each time point represent $40 \%$ and $50 \%$ of total intracellular and secreted apoB, respectively; $10 \%$ of total intracellular and $2 \%$ of total secreted albumin are also shown. Results with $\mathrm{Ldll}^{-/-}$cells are representative of results obtained with adenoviral infection of wild-type hepatocytes ( $n=4$ independent isolations).

An even more extreme demonstration that lipid supply alone cannot drive apoB secretion in vivo was recently reported. Mice constitutively expressing the mature, active form of SREBP-1a, a transcription factor responsible for activating several genes encoding lipogenic enzymes, have severe fatty liver. These animals have a large enhancement in hepatic neutral lipid synthesis, without a concomitant increase in VLDL secretion (25). If the LDL receptor promotes degradation of newly synthesized apoB and thus limits VLDL secretion even in the presence of a large neutral lipid pool, then our data predict that loss of the LDL receptor should reverse this effect. Indeed, Horton et al. (26) recently reported that $\mathrm{Ldll}^{-/}$mice constitutively expressing SREBP-1a have dramatic hypertriglyceridemia due to enhanced VLDL production.

$A p o B$ is constitutively synthesized in the liver (52-54). However, $40-60 \%$ of newly synthesized apoB is degraded rather than secreted (19). Consequently, the rate of apoB secretion is largely determined by the ability of newly synthesized apoB to escape degradation $(20,21)$. In the present study, kinetic modeling estimated that $55 \%$ of newly synthesized apoB100 was targeted for degradation (Figure 4a, Table 2). This was not the case in hepatocytes lacking a functional LDL receptor, in which there was little post-translational apoB degradation.

We cannot rule out the possibility that in both wildtype and $\mathrm{Ldl}^{-1}$ - hepatocytes, a pool of newly synthesized apoB is cotranslationally degraded and therefore cannot be traced, even with a pulse time as short as 7.5 minutes. We tried to obtain evidence of such a pool by using proteasome inhibitors. However, none of the inhibitors used (ALLN, MG-132) affected apoB degradation, in agreement with recent work of White et al. (55).

In the pulse-chase experiments (Figure 4), we observed continued incorporation of radiolabel into both apoB and albumin during the initial chase period, even after a wash with unlabeled medium and continued incubation in the presence of 1,000 -fold excess unlabeled methionine and cysteine. Continued radiolabel incorporation is reflected in the "disparity" between the amount of secreted protein and "peak" intracellular protein levels (compare secreted apoB levels at 4 hour to intracellular levels at 30 minutes from $\mathrm{Ldlr}^{-/}$hepatocytes; Figure 4a).

Because translation of full-length apoB requires

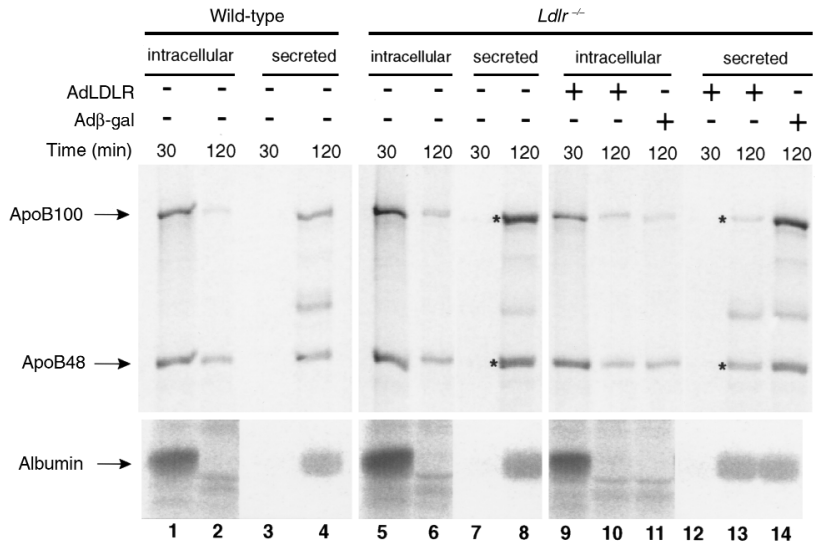

approximately 20 minutes (56), the fact that amino acid tracer will first be incorporated into the $\mathrm{COOH}$-terminus of almost completed polypeptide chains has to be considered in interpreting the data. As the radiolabeling period continues, tracer will be incorporated along the full-length of polypeptide chains. Even after the chase has started, there is some radiolabeled amino acid that has already been incorporated into the $\mathrm{NH}_{2}$-terminus of newly initiated apoB chains. This accounts for the continued appearance of radiolabeled protein during the chase. As a result, the intracellular pool of newly synthesized apoB includes all 3 groups of protein just described. This is taken into account in the multicompartmental modeling by inclusion of compartments 2-6 (Figure 1), which represent tracer incorporation into progressively longer apoB nascent chains. Based on this scenario, the initial $\mathrm{COOH}$-terminal radiolabeled proteins will be detectable at least 20 minutes before newly initiated polypeptide chains; $\mathrm{NH}_{2}$-terminally radiolabeled peptide chains will continue to be translated up to 20 minutes after newly initiated chains are detected. In the pulse-chase data presented in Figure 4, the period after removal of the amino acid tracer, during which intracellular apoB radioactivity continues to rise, is due to continued incorporation of tracer into apoB.

The amount of product (secreted apoB) that can theoretically be measured is equivalent to the pool of synthesized precursor (cellular apoB represented as compartments 7, 8, and 10 in the multicompartmental model; Figure 1). The amount of secreted apoB (compartment 9; Figure 1) represents the total amount of precursor produced and will equal the amount of precursor, assuming no degradation. However, the pool of newly synthesized apoB, by the nature of the experiment, includes the peak intracellular levels as well as the protein that remains to be translated. Hence, the cellular pool of apoB is most accurately represented by the area under the curve, which is the integral of the flux of tracer through the compartments (amount of radiolabel per unit of time). One important consequence is that estimating the amount of apoB synthesized at a single time point (e.g., comparing the intracellular "peak" protein level to the plateau secreted level) greatly underestimates the total amount synthesized. This in turn results in an 
underestimation of the extent of post-translational degradation. Taken together, these concepts explain the finding that when there is relatively little post-translational degradation (e.g., albumin in either cell type, or apoB in $\mathrm{Ldlr}^{-/}$hepatocytes; Figure 4; Table 2), the plateau of the secreted protein curve is higher than the peak of the intracellular protein curve.

Reuptake of newly secreted VLDL has been proposed as a mechanism by which the LDL receptor might attenuate VLDL secretion (22). To estimate the contribution of reuptake to net apoB secretion from primary hepatocytes, we blocked apoB binding to glycosaminoglycans and to the LDL receptor with heparin. As estimated by multicompartmental modeling, approximately $32 \%$ of nascent apoB100 destined for degradation was present in this heparin-accessible pool and was rescued from degradation in wild-type hepatocytes upon heparin addition (Figure 4a; Table 2).

Davis et al. showed that primary rat hepatocytes do not internalize newly secreted VLDL that has been harvested from tissue culture media and added back to the cells (57). In addition, primary rat hepatocytes have been shown to have a very low capacity for uptake and degradation of LDL (58). We interpret the ability of heparin to rescue apoB from degradation as indicative of LDL receptor-mediated reuptake and subsequent degradation of apoB-containing lipoproteins. We can reconcile these apparently contradictory results by proposing that newly synthesized VLDL is not functionally equivalent to particles in the fluid phase. Williams et al. showed that a pool of VLDL could be released to the fluid phase when cells were shaken, consistent with a pool of cell-surface trapped VLDL (22). Thus, we propose that a cell-associated pool of VLDL is a ligand for LDL receptor-mediated reuptake, but fluid-phase VLDL is a poor ligand for reuptake.

There was more presecretory, post-translational degradation of apoB100 than apoB48 in the wild-type mouse hepatocytes, consistent with prior studies in rat hepatocytes (59). One possible explanation for this difference is that apoB100 contains the principal LDL receptor-binding domain of $\mathrm{apoB}(60,61)$ and is thus more sensitive to the presence or absence of the LDL receptor. However, heparin rescue of both apoB100 and apoB48 with wildtype cells, and of apoB100 from $\mathrm{Ldlr}^{-/}$cells, suggests a role for apoB and/or apoE proteoglycan-binding domains (e.g., ref. 62) in mediating apoB clearance. Even though a single amino acid substitution abolishes proteoglycan binding of apoB100 (63), the $\mathrm{NH}_{2}$-terminus of apoB (apoB17) is sufficient to mediate an interaction between lipoproteins and proteoglycans (64), consistent with proteoglycan binding by both apoB100 and apoB48. Adenovirus-mediated LDL receptor overexpression greatly diminished apoB secretion. Again, apoB100 was affected to a larger degree than was apoB48. Secretion of both apoB forms was reduced, and their degradation concomitantly increased (Figure 5), whereas synthesis of albumin, a control secreted protein, was unaffected. Because a reduction in intracellular apoB levels was vis- ible by 30 minutes (Figure 5, lane 5 versus lane 9), we postulate that the LDL receptor interacts with apoB before secretion of the apoB-containing lipoprotein particle. In this manner, the LDL receptor may affect apoB's residence time within the secretory pathway. This hypothesis is consistent with several findings. First, transport of apoB from the endoplasmic reticulum (ER) to the Golgi is a rate-limiting step in apoB secretion $(19,65,66)$. And second, studies of transgenic SREBP-1a mice demonstrated that the relative secretion efficiency of VLDL is higher in $\mathrm{Ldlr}^{-/}$animals (26).

Because both apoB and the LDL receptor coexist within the secretory pathway with the ligand-binding domain of the LDL receptor oriented toward the ER lumen, an intracellular interaction between the LDL receptor and either apoB or apoE associated with apoBcontaining particles could alter the post-translational fate of apoB. Such an interaction could make apoB more protease accessible. Consistent with this prediction, elevated levels of the LDL receptor reduced intracellular apoB levels in $\mathrm{Ldlr}^{-/}$hepatocytes (Figure 6).

There is precedent for intra-ER protein-protein interactions serving as agonists of protein export (reviewed in ref. 67). For example, general chaperones promote folding and prevent premature protein export. Likewise, receptor-associated protein (RAP) acts as substrate analog to prevent premature apoE binding to LDL receptor-related protein (LRP; reviewed in ref. 68) and also assists in the proper folding of LRP (69). In contrast, protein-specific ligands can act as direct antagonists of protein export: for example, egasyn blocks export of $\beta$-glucuronidase by retaining it within the ER $(70,71)$. There is also precedent for protein-protein interactions within the ER antagonizing export by targeting a protein for degradation. Interaction with the HIV protein $v p u$ (gp160) targets the T-cell receptor CD4 for ER degradation, resulting in a decrease in cellsurface CD4 expression (reviewed in ref. 72).

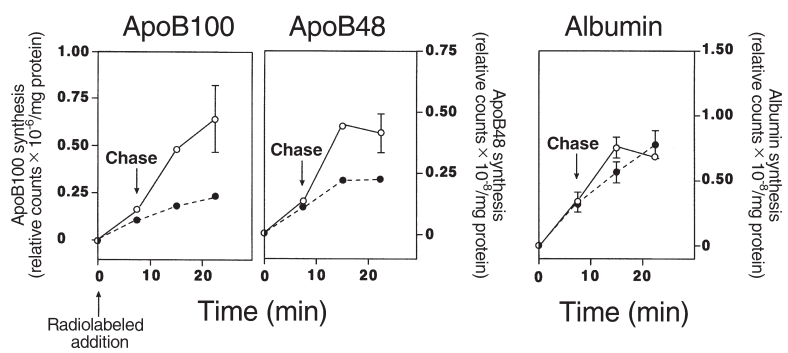

\section{Figure 6}

Determination of intracellular apoB and albumin levels after adenovirus-mediated overexpression of the LDL receptor. Adenovirus infection was as described in the legend to Figure 5. Ldlr-/- hepatocytes were radiolabeled for 7.5 minutes with [ $\left.{ }^{35} \mathrm{~S}\right]$ methionine/cysteine in the presence of heparin $(6 \mathrm{mg} / \mathrm{mL})$, washed once, and chased for the indicated times. Chase times are relative to the addition of radiolabel. Results are the mean of duplicate samples from a single hepatocyte isolation and are representative of results obtained with wild-type cells. Error bars represent the variance between duplicate samples; error bars that are not visible are smaller than the symbol. Open circle, intracellular; filled circle, intracellular + Ad LDLR. There was no detectable apoB secretion by 22.5 minutes. 


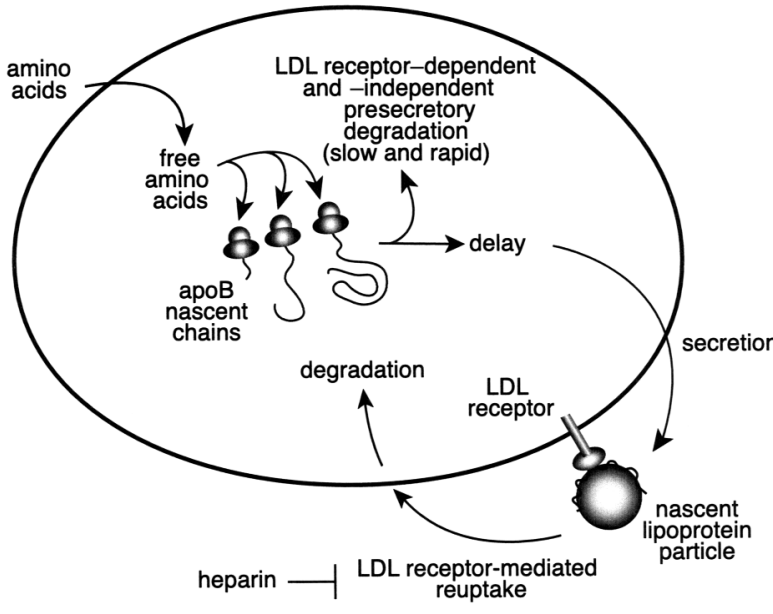

Figure 7

Model of apoB secretion and degradation. Amino acid incorporation into increasingly longer apoB nascent chains is depicted. As apoB transits the secretory pathway, presecretory degradation occurs via both LDL receptor-dependent and-independent means that are either rapid or slow. The nascent lipoprotein particle ultimately reaches the cell surface, at which point the LDL receptor can mediate its reuptake; this results in internalization and subsequent turnover of apoB. This final degradation pathway is inhibited by addition of heparin.

Our results lead us to propose the following working model (Figure 7). As apoB enters the secretory pathway, presecretory degradation occurs via both LDL receptor-dependent and -independent mechanisms. A temporary arrest of apoB translocation (73), or an extended association between apoB and the translocon (74) as it enters the ER, could facilitate an interaction between apoB and the LDL receptor. Rapid and slow presecretory apoB degradation may occur in the ER or in a postER compartment (e.g., ref. 59, 75, 76). The nascent lipoprotein particle ultimately reaches the cell surface, where the LDL receptor can mediate its reuptake, resulting in internalization and subsequent turnover of apoB. This cell-surface event can be interrupted by heparin, resulting in "rescue" of apoB secretion.

Our results address several long-standing paradoxes and make specific testable predictions. While providing direct evidence for increased production of lipoproteins in hepatocytes in the absence of a functional receptor, we provide a working model to explain why increased VLDL secretion is not always observed in patients with FH. Our model predicts that the type of LDL-receptor mutation will affect the rate of VLDL secretion; only functionally null mutations, as used in this study, will result in VLDL overproduction. Receptors that are trapped within the secretory pathway may still attenuate apoB100 secretion. This prediction is borne out in studies of the WHHL rabbit, an FH model with LDL receptors that stall in the ER but retain ligand-binding capacity (77). VLDL secretion from perfused WHHL liver (78) or from cultured WHHL hepatocytes (79) is similar to wild-type rabbit liver and hepatocytes, respectively.

Drugs that inhibit HMG-CoA reductase (statins) appear to be ineffective in patients with null mutations in the LDL receptor (12). In numerous in vivo lipoprotein turnover studies, statins lower LDL levels by decreasing LDL production rather than by increasing LDL catabolism (13-17). In many of the studies, statins also inhibit VLDL secretion $(15,80,81)$. Apparently, the effect on VLDL secretion is through enhanced posttranslational degradation of apoB (82). Our studies address this issue by linking LDL-receptor expression with post-translational apoB degradation. If functional LDL receptors are required for post-translational apoB degradation, then statins could increase apoB degradation through their well-known ability to upregulate LDL receptor gene transcription (11).

If the mechanism of statin action involves an intracellular receptor-ligand interaction, then null mutations should confer a lack of response to statins while LDL receptors that arrest in the ER but still bind ligand might be upregulated, and thus decrease apoB secretion. Consistent with this model, the $\mathrm{Ldlr}^{-/}$mouse, when treated with statins, does not decrease its rate of apoB secretion (in fact, there is a paradoxical increase in apoB secretion with chronic Atorvastatin [Parke-Davis, Ann Arbor, Michigan, USA] treatment; ref. 83). The WHHL rabbit, an animal with a type $2 \mathrm{LDL}$ receptor mutation, responds to statins (84), but apoB production has not been measured in statin-treated WHHL rabbits. In addition, in a recent study, patients with $\mathrm{FH}$ with mutations analogous to that of the WHHL rabbit respond to statins with a decrease in LDL production and no increase in LDL clearance (85). Given that VLDL production was not measured in this study, we cannot infer whether the change in LDL production was a consequence of altered VLDL production. However, like the $L d l r^{-1}$ mice, patients with functionally null mutations are unresponsive to statin therapy (85).

Our model makes another testable prediction. Because apoE is a ligand for the LDL receptor and is also synthesized in the liver, apoE might compete with apoB for binding to the LDL receptor within the secretory pathway and/or at the cell surface. Our model predicts that such a competition would affect the rate of VLDL apoB secretion. Consistent with this prediction, in transgenic mouse models there is a clear correlation between the level of apoE expression and the rate of apoB secretion. ApoE ${ }^{\text {null/null }}$ mice have impaired apoB secretion and suffer from fatty liver (86). Conversely, transgenic mice overexpressing apoE have hypertriglyceridemia due to a combination of enhanced VLDL secretion and decreased lipoprotein lipase-mediated lipolysis of VLDL (87). Finally, hepatoma cells overexpressing human apoE secrete VLDL at a higher rate (87). This effect was blocked by prior treatment with heparinase, indicating that it was primarily mediated through an interaction at the cell surface. Because there is a large pool of cell surface-bound apoE $(88,89)$, reuptake of VLDL is likely to be modulated by apoE expression in vivo.

In summary, we show a direct link between functional LDL receptor expression and post-translational apoB degradation. ApoB turnover occurs via 
LDL receptor-mediated reuptake of apoB-containing lipoproteins and their degradation. In addition, both LDL receptor-dependent and-independent presecretory mechanisms contribute to turnover of newly synthesized apoB.

These results provide a new framework for investigating the nature of lipoprotein overproduction in familial hypercholesterolemia. In addition, they provide a new model to explain how particular types of LDL-receptor mutations uncouple the 2 kinetic defects associated with $\mathrm{FH}$, decreased LDL catabolism and overproduction of LDL. Although there are likely multiple mechanisms by which HMG-CoA reductase inhibitors affect lipoprotein production, the data help in understanding why LDL-receptor function correlates with responsiveness to these drugs.

\section{Acknowledgments}

We thank R. Davis and members of the Attie lab, in particular, S. Nadler and J. Stoehr, for helpful discussions regarding the manuscript. The anti-MTP 97-kDa subunit antibody was a generous gift of $\mathrm{H}$. Jamil; the human LDL receptor adenovirus was a kind gift of J. Wilson. This study was supported by grants from the National Institutes of Health (HL-56595 to A.D. Attie and NCRR R12609 to P.H.R. Barrett). D.L. Gillian-Daniel was the recipient of a Postdoctoral Fellowship from the American Heart Association Northland Affiliate and of a National Institutes of Health Postdoctoral Training Grant (Nutritional Sciences Department; DK 07665).

1. Langer, T., Stober, W., and Levy, R.I. 1972. The metabolism of LDL in familial type II hyperlipidemia. J. Clin. Invest. 51:1528-1536.

2. Bilheimer, D.W., Stone, N.J., and Grundy, S.M. 1979. Metabolic studies in familial hypercholesterolemia. Evidence for a gene-dosage effect in vivo. J. Clin. Invest. 64:524-533.

3. Pittman, R.C., et al. 1982. Tissue sites of degradation of low density lipoprotein in normal rabbits and in a receptor-negative mutant strain (WHHL rabbit). J. Biol. Chem. 257:7994-8000.

4. Brown, M.S., and Goldstein, J.L. 1986. A receptor-mediated pathway for cholesterol homeostasis. Science. 232:34-47.

5. Packard, C.J., et al. 1976. Low density lipoprotein metabolism in a family of familial hypercholesterolemic patients. Metabolism. 25:995-1006.

6. Soutar, A.K., Myant, N.B., and Thompson, G.R. 1977. Simultaneous measurement of apolipoprotein B turnover in very-low- and low-density lipoproteins in familial hypercholesterolaemia. Atherosclerosis. 28:247-256.

7. James, R.W., et al. 1989. Apolipoprotein B metabolism in homozygous familial hypercholesterolemia. J. Lipid Res. 30:159-169.

8. Havel, R.J., and Kane, J.P. 1995. Introduction: structure and metabolism of plasma lipoproteins. In The metabolic and molecular bases of inherited disease. Volume II. C.R. Scriver, A.L. Beaudet, W.S. Sly, and D. Valle, editors. McGraw-Hill. New York, NY. 1841-1851.

9. Bilheimer, D.W., Watanabe, Y., and Kita, T. 1982. Impaired receptor-mediated catabolism of low density lipoprotein in the WHHL rabbit, an animal model of familial hypercholesterolemia. Proc. Natl. Acad. Sci. USA. 79:3305-3309.

10. Endo, A. 1992. The discovery and development of HMG-CoA reductase inhibitors. J. Lipid Res. 33:1569-1582.

11. Ma, P.T., et al. 1986. Mevinolin, an inhibitor of cholesterol synthesis, induces mRNA low density lipoprotein receptor in livers of hamsters and rabbits. Proc. Natl. Acad. Sci. USA. 83:8370-8374.

12. Uauy, R., Vega, G.L., Grundy, S.M., and Bilheimer, D.M. 1988. Lovastatin therapy in receptor-negative homozygous familial hypercholesterolemia: lack of effect on low-density lipoprotein concentration or turnover. J. Pediatr. 113:387-392.

13. Grundy, S.M., and Vega, G.L. 1985. Influence of mevinolin on metabolism of low density lipoprotein in primary moderate hypercholesterolemia. J. Lipid Res. 26:1464-1475.

14. Arad, Y., Ramakrishnan, R., and Ginsberg, H.N. 1990. Lovastatin therapy reduces low density lipoprotein apoB levels in subjects with combined hyperlipidemia by reducing the production of apoB-containing lipoproteins: implications for the pathophysiology of apoB production. J. Lipid Res. 31:567-582.

15. Cuchel, M., et al. 1997. Lovastatin decreases de novo cholesterol synthesis and LDL apo B-100 production rates in combined-hyperlipidemic males. Arterioscler. Thromb. Vasc. Biol. 17:1910-1917.

16. Huff, M.W., Telford, D.E., Woodcroft, K., and Strong, W.L.P. 1985. Mevinolin and cholestryramine inhibit the direct synthesis of low density lipoprotein apolipoprotein B in miniature pigs. J. Lipid Res. 26:1175-1186.

17. Auerbach, B.J., Krause, B.R., Bisgaier, C.L., and Newton, R.S. 1995. Comparative effects of HMG-CoA reductase inhibitors on apo-B production in the casein-fed rabbit: atorvastatin versus lovastatin. Atherosclerosis. 115:173-180.

18. Huff, M.W., and Burnett, J.R. 1997. 3-hydroxy-3-methylglutaryl coenzyme A reductase inhibitors and hepatic apolipoprotein B secretion. Curr. Opin. Lipidol. 8:138-145.

19. Borchardt, R.A., and Davis, R.A. 1987. Intrahepatic assembly of very low density lipoproteins. Rate of transport out of the endoplasmic reticulum determines rate of secretion. J. Biol. Chem. 262:16394-16402.

20. Dixon, J.L., and Ginsberg, H.N. 1993. Regulation of hepatic secretion of apolipoprotein B-containing lipoproteins: information obtained from cultured liver cells. J. Lipid Res. 34:167-179.

21. Yao, Z., Tran, K., and McLeod, R.S. 1997. Intracellular degradation of newly synthesized apolipoprotein B. J. Lipid Res. 38:1937-1953.

22. Williams, K.J., Broci, R.W., and Fisher, E.A. 1990. The unstirred water layer as a site of control of apolipoprotein B secretion. J. Biol. Chem. 265:16741-16744.

23. Ishibashi, S., et al. 1993. Hypercholesterolemia in low density lipoprotein receptor knockout mice and its reversal by adenovirus-mediated gene delivery. J. Clin. Invest. 92:883-893.

24. Ishibashi, S., et al. 1994. Massive xanthomatosis and atherosclerosis in cholesterol-fed low density lipoprotein receptor-negative mice. J. Clin. Invest. 93:1885-1893.

25. Shimano, H., et al. 1996. Overproduction of cholesterol and fatty acids causes massive liver enlargement in transgenic mice expressing truncated SREBP-1a. J. Clin. Invest. 98:1575-1584.

26. Horton, J.D., Shimano, H., Hamilton, R.L., Brown, M.S., and Goldstein, J.L. 1999. Disruption of LDL receptor gene in transgenic SREBP-1a mice unmasks hyperlipidemia resulting from production of lipid-rich VLDL. J. Clin. Invest. 103:1067-1076.

27. Gaw, A., Mancini, F.P., and Ishibashi, S. 1995. Rapid genotyping of low-density-lipoprotein receptor knockout mice using a polymerase chain-reaction technique. Lab. Anim. 29:447-449.

28. Princen, H.M.G., Huijsmans, C.M.G., Kuipers, F., Vonk, R., and Kempen, H.J.M. 1986. Ketoconazole blocks bile acid synthesis in hepatocyte monolayer cultures and in vivo in rat by inhibiting cholesterol 7a-hydroxylase.J. Clin. Invest. 78:1064-1071.

29. Laemmli, U.K. 1970. Cleavage of structural proteins during the assembly of the head of bacteriophage T4. Nature. 227:680-686.

30. Lowry, O.H., Rosebrough, N.J., Farr, A.L., and Randall, R.J. 1951. Protein measurement with the Folin phenol reagent. J. Biol. Chem. 193:265-275.

31. Wilcox, L.J., Barrett, P.H., and Huff, M.W. 1999. Differential regulation of apolipoprotein B secretion from HepG2 cells by two HMG-CoA reductase inhibitors, atorvastatin and simvastatin. J. Lipid Res. 40:1078-1089.

32. Gianturco, S.H., and Bradley, W.A. 1986. The role of apolipoprotein processing in receptor recognition of VLDL. Methods Enzymol. 129:319-344.

33. Bligh, E.G., and Dyer, W.J. 1959. A rapid method of total lipid extraction and purification. Can. J. Biochem. Physiol. 37:911-917.

34. Chomczynski, P., and Sacchi, N. 1987. Single-step method of RNA isolation by acid guanidinium thiocyanate-phenol-chloroform extraction. Anal. Biochem. 162:156-159.

35. Hussain, M.M., Zhao, Y., Kancha, R.K., Blackhart, B.D., and Yao, Z. 1995. Characterization of recombinant human ApoB-48-containing lipoproteins in rat hepatoma McA-RH7777 cells transfected with ApoB-48 cDNA: overexpression of ApoB-48 decreases synthesis of endogenous ApoB-100. Arterioscler. Thromb. Vasc. Biol. 15:485-494.

36. Fort, P.H., et al. 1985. Various rat adult tissues express only one major mRNA species from the glyceraldehyde-3-phosphate dehydrogenase multigenic family. Nucleic Acids Res. 13:1431-1442.

37. Krawczyk, Z., and Wu, C. 1987. Isolation of RNA for dot hybridization by heparin-DNase I treatment of whole cell lysate. Anal. Biochem. 162:156-159.

38. Seoane, J., et al. 1996. Glucose 6-phosphate produced by glucokinase, but not hexokinase I, promotes the activation of hepatic glycogen synthase. J. Biol. Chem. 271:23756-23760.

39. Chan, L., Chang, B.H.J., Nakamuta, M., Li, W.H., and Smith, L.C. 1997. Apobec-1 and apolipoprotein B mRNA editing. Biochim. Biophys. Acta. 1345:11-26.

40. Greeve, J., Altkemper, I., Dieterich, J.H., Greten, H., and Windler, E. 1993. Apolipoprotein B mRNA editing in 12 different mammalian species: hepatic expression is reflected in low concentrations of apoB-containing plasma lipoproteins. J. Lipid Res. 34:1367-1383.

41. Higuchi, K., Kitagawa, K., Kogishi, K., and Takeda, T. 1992. Developmen- 
tal and age-related changes in apolipoprotein B mRNA editing in mice. $J$. Lipid Res. 33:1753-1764.

42. Gibson, J.C., et al. 1987. Plasma lipoprotein distribution of apolipoprotein $\mathrm{E}$ in familial hypercholesterolemia. Arteriosclerosis. 7:401-407.

43. Thompson, G.R., Naoumova, R.P., and Watts, G.F. 1996. Role of cholesterol in regulating apolipoprotein B secretion by the liver. J. Lipid Res. 37:439-447.

44. Wetterau, J.R., Lin, M.C., and Jamil, H. 1997. Microsomal triglyceride transfer protein. Biochim. Biophys. Acta. 1345:136-150.

45. Tietge, U.J.F., et al. 1999. Hepatic overexpression of microsomal triglyceride transfer protein (MTP) results in increased in vivo secretion of VLDL triglycerides and apolipoprotein B. J. Lipid Res. 40:2134-2139.

46. Raabe, M., et al. 1998. Knockout of the abetalipoproteinemia gene in mice: reduced lipoprotein secretion in heterozygotes and embryonic lethality in homozygotes. Proc. Natl. Acad. Sci. USA. 95:8686-8691.

47. Goldstein, J.L., Basu, S.K., Brunschede, G.Y., and Brown, M.S. 1976. Release of low density lipoprotein from its cell surface receptor by sulfated glycosaminoglycans. Cell. 7:85-95.

48. Powell-Braxton, L., et al. 1998. A mouse model of human familial hypercholesterolemia: markedly elevated low density lipoprotein cholesterol levels and severe atherosclerosis on a low-fat chow diet. Nat. Med. 4:934-938.

49. Veniant, M.M., et al. 1998. Lipoprotein clearance mechanisms in LDL receptor-deficient "Apo-B48-only" and "Apo-B100-only" mice. J. Clin. Invest. 102:1559-1568.

50. Ishibashi, S., Herz, J., Maeda, N., Goldstein, J.L., and Brown, M.S. 1994. The two-receptor model of lipoprotein clearance: tests of the hypothesis in "knockout" mice lacking the low density lipoprotein receptor, apolipoprotein E, or both proteins. Proc. Natl. Acad. Sci. USA. 91:4431-4435.

51. Patsch, W., Tamai, T., and Schonfeld, G. 1983. Effect of fatty acids on lipid and apoprotein secretion and association in hepatocyte cultures. J. Clin. Invest. 72:371-378.

52. Sorci-Thomas, M., Wilson, M.D., Johnson, F.L., Williams, D.L., and Rudel, L.L. 1989. Studies on the expression of genes encoding apolipoproteins $\mathrm{B} 100$ and B48 and the low density lipoprotein receptor in nonhuman primates. Comparison of dietary fat and cholesterol. J. Biol. Chem. 264:9039-9045.

53. Pullinger, C.R., et al. 1989. The apolipoprotein B gene is constitutively expressed in HepG2 cells: regulation of secretion by oleic acid, albumin, and insulin, and measurement of the mRNA half-life. J. Lipid Res. 30:1065-1077.

54. Moberly, J.B., Cole, T.G., Alpers, D.H., and Schonfeld, G. 1990. Oleic acid stimulation of apolipoprotein B secretion from HepG2 and Caco-2 cells occurs post-transcriptionally. Biochim. Biophys. Acta. 1042:70-80.

55. White, A.L., Guerra, B., Wang, J., and Lanford, R.E. 1999. Presecretory degradation of apolipoprotein [a] is mediated by the proteasome pathway.J. Lipid Res. 40:275-286.

56. Benoist, F., and Grand-Perret, T. 1997. Co-translational degradation of apolipoprotein $\mathrm{B} 100$ by the proteasome is prevented by microsomal triglyceride transfer protein. J. Biol. Chem. 272:20435-20442.

57. Davis, R.A., Boogaerts, J.R., Borchardt, R.A., Malone-McNeal, M., and Archambault-Schexnayder, J. 1985. Intrahepatic assembly of very low density lipoproteins. Varied synthetic response of individual apolipoproteins to fasting. J. Biol. Chem. 260:14137-14144.

58. Attie, A.D., Pittman, R.C., and Steinberg, D. 1980. Metabolism of native and of lactosylated human low density lipoprotein: evidence for two pathways for catabolism of exogenous proteins in rat hepatocytes. Proc. Natl. Acad. Sci. USA. 77:5923-5927.

59. Wang, C.N., Hobman, T.C., and Brindley, D.N. 1995. Degradation of apolipoprotein B in cultured rat hepatocytes occurs in a post-endoplasmic reticulum compartment. J. Biol. Chem. 270:24924-24931.

60. Welty, F.K., Seman, L., and Yen, F.T. 1995. Purification of the apolipoprotein B-67-containing low density lipoprotein particle and its affinity for the low density lipoprotein receptor. J. Lipid Res. 36:2622-2629.

61. Borén, J., et al. 1998. Identification of the low density lipoprotein receptorbinding site in apolipoprotein B100 and the modulation of its binding activity by the carboxyl terminus in familial defective apo-B100. J. Clin. Invest. 101:1084-1093.

62. Weisgraber, K.H., and Rall, S.C. 1987. Human apolipoprotein B-100 heparin-binding sites. J. Biol. Chem. 262:11097-11103.

63. Borén, J., et al. 1998. Identification of the principal proteoglycan-binding site in LDL. A single-point mutation in apo-B100 severely affects proteoglycan interaction without affecting LDL receptor binding. J. Clin. Invest. 101:2658-2664.

64. Goldberg, I.J., et al. 1998. The NH2-terminal region of apolipoprotein B is sufficient for lipoprotein association with glycosaminoglycans. J. Biol. Chem. 273:35355-35361.

65. Alexander, C.A., Hamilton, R.L., and Havel, R.J. 1976. Subcellular localization of B apoprotein of plasma lipoproteins in rat livers. J. Cell Biol. 69:241-263.
66. Cartwright, I.J., Hebbachi, A., and Higgins, J.A. 1993. Transit and sorting of apolipoprotein B within the endoplasmic reticulum and Golgi compartments of isolated hepatocytes from normal and orotic acid-fed rats. J. Biol. Chem. 268:20937-20952.

67. Aridor, M., and Balch, W.E. 1999. Integration of endoplasmic reticulum signaling in health and disease. Nat. Med. 5:745-751.

68. Bu, G., and Schwartz, A.L. 1998. RAP, a novel type of ER chaperone. Trends Cell Biol. 8:272-276.

69. Bu, G., and Rennke, S. 1996. Receptor-associated protein is a folding chaperone for low density lipoprotein receptor-related protein. J. Biol. Chem. 271:22218-22224.

70. Zhen, L., Baumann, H., Novak, E.K., and Swank, R.T. 1993. The signal for retention of the egasyn-glucuronidase complex within the endoplasmic reticulum. Arch. Biochem. Biophys. 304:402-414.

71. Zhen, L., Rusiniak, M.E., and Swank, R.T. 1995. The beta-glucuronidase propeptide contains a serpin-related octamer necessary for complex formation with egasyn esterase and for retention within the endoplasmic reticulum. J. Biol. Chem. 270:11912-11920.

72. Geleziunas, R., Bour, S., and Wainberg, M.A. 1994. Cell surface down-modulation of CD4 after infection by HIV-1. FASEB J. 8:593-600.

73. Chuck, S.L., and Lingappa, V.R. 1992. Pause transfer: a topogenic sequence in apolipoprotein B mediates stopping and restarting of translocation. Cell. 68:9-21.

74. Mitchell, D.M., et al. 1998. Apoprotein B100 has a prolonged interaction with the translocon during which its lipidation and translocation change from dependence on the microsomal triglyceride transfer protein to independence. Proc. Natl. Acad. Sci. USA. 95:14733-14738.

75. Davis, R.A., et al. 1989. Intrahepatic assembly of very low density lipoproteins: immunologic characterization of apolipoprotein B in lipoproteins and hepatic membrane fractions and its intracellular distribution. J. Lipid Res. 30:1185-1196.

76. Wu, X., et al. 1997. A two-site model for apoB degradation in HepG2 cells. J. Biol. Chem. 272:11575-11580.

77. Yamamoto, T., Bishop, R.W., Brown, M.S., Goldstein, J.L., and Russell, D.W. 1986. Deletion in cysteine-rich region of LDL receptor impedes transport to cell surface in WHHL rabbit. Science. 232:1230-1237.

78. Hornick, C.A., Kita, T., Hamilton, R.L., Kane, J.P., and Havel, R.J. 1983. Secretion of lipoproteins from the liver of normal and Watanabe heritable hyperlipidemic rabbits. Proc. Natl. Acad. Sci. USA. 80:6096-6100.

79. Tanaka, M., Otani, H., Yokode, M., and Kita, T. 1995. Regulation of apolipoprotein B secretion in hepatocytes from Watanabe heritable hyperlipidemic rabbit, an animal model of familial hypercholesterolemia. Atherosclerosis. 114:73-82.

80. Ginsberg, H.N., Le, N.A., Short, M.P., Ramakrishnan, R., and Desnick, R.J. 1987. Suppression of apolipoprotein B production during treatment of cholesteryl ester storage disease with lovastatin. Implications for regulation of apolipoprotein B synthesis. J. Clin. Invest. 80:1692-1697.

81. Vega, G.L., Krauss, R.M., and Grundy, S.M. 1990. Pravastatin therapy in primary moderate hypercholesterolaemia: changes in metabolism of apolipoprotein B-containing lipoproteins. J. Intern. Med. 227:81-94.

82. Mohammadi, A., et al. 1998. Effects of Atorvastatin on the intracellular stability and secretion of apolipoprotein B in HepG2 cells. Arterioscl. Thromb. Vasc. Biol. 18:783-793.

83. Bisgaier, C.L., et al. 1997. Attenuation of plasma low density lipoprotein cholesterol by select 3-hydroxy-3-methylglutaryl coenzyme A reductase inhibitors in mice devoid of low density lipoprotein receptors. J. Lipid Res. 38:2502-2515.

84. Carew, T.E., Schwenke, D.C., and Steinberg, D. 1987. Antiatherogenic effect of probucol unrelated to its hypocholesterlemic effect: evidence that antioxidants in vivo can selectively inhibit low density lipoprotein degradation in macrophage-rich fatty streaks and slow the progression of atherosclerosis in the Watanabe heritable hyperlipidemic rabbit. Proc. Natl. Acad. Sci. USA. 84:7725-7729.

85. Marais, A.D., et al. 1997. Decreased production of low density lipoprotein by atorvastatin after apheresis in homozygous familial hypercholesterolemia. J. Lipid Res. 38:2071-2078.

86. Kuipers, F., et al. 1997. Impaired secretion of very low density lipoproteintriglycerides by apolipoprotein E-deficient mouse hepatocytes. J. Clin. Invest. 100:2915-2922.

87. Huang, Y., et al. 1998. Overexpression and accumulation of apolipoprotein E as a cause of hypertriglyceridemia. J. Biol. Chem. 273:26388-26393.

88. Zhao, Y., and Mazzone, T. 1999. LDL receptor binds newly synthesized apoE in macrophages. A precursor pool for apoE secretion. J. Lipid Res. 40:1029-1035.

89. Schmitt, M., and Grand-Perret, T. 1999. Regulated turnover of a cell surface-associated pool of newly synthesized apolipoprotein E in HepG2 cells. J. Lipid Res. 40:39-49. 